\title{
Pepper Mild Mottle Virus Coat Protein Alone Can Elicit the Capsicum spp. $L^{3}$ Gene-Mediated Resistance
}

\author{
P. Gilardi, I. García-Luque, and M. T. Serra \\ Departamento de Biología de Plantas, Centro de Investigaciones Biológicas (CSIC), Velázquez 144, 28006- \\ Madrid, Spain \\ Accepted 4 August 1998.
}

\begin{abstract}
The pepper mild mottle virus (PMMoV-S) (an $L^{3}$ hypersensitive response [HR]-inducer strain) coat protein was expressed in Capsicum chinense $\left(L^{3} L^{3}\right)$ plants with the heterologous potato virus X (PVX)-based expression system. The chimeric virus was localized in the inoculated leaves and induced the HR, thus indicating that the tobamoviral sequences that affect induction of the HR conferred by the $L^{3}$ resistance gene reside in the coat protein gene. Furthermore, transient expression of the PMMoV-S coat protein in $C$. chinense leaves by biolistic co-bombardment with a plasmid expressing the $\beta$-glucuronidase (GUS) gene leads to the induction of cell death and expression of host defense genes. Thus, the coat protein of PMMoV-S is the elicitor of the Capsicum spp. $L^{3}$ resistance gene-mediated HR.
\end{abstract}

Plants have evolved a broad and diverse array of defense mechanisms against potential pathogens. Some of these mechanisms are established in the plant before the arrival of the pathogen, whereas others are inducible upon the perception of pathogenic signals. One form of induced response is the hypersensitive response (HR) (Klement 1982; Goodman and Novacky 1994), a highly pathogen-specific reaction involving a rapid plant cell death at the site of infection as well as the activation of a cascade of host genes that leads to the inhibition of pathogen multiplication and spread within the infected plant (Bol et al. 1990; Stinzi et al. 1993).

The HR is the most characteristic defense response associated with gene-for-gene interactions (Flor 1971). Recent cloning and molecular characterization of plant resistance $(R)$ genes and corresponding pathogen avirulence (Avr) genes (Staskawicz et al. 1995; Bent 1996) have provided support for the proposed recognition model between products of complementary $R$ genes in the host and $A v r$ genes in the pathogen side (Gabriel and Rolfe 1990; Keen 1990). Furthermore, direct evidence for a receptor-elicitor interaction has been obtained (Tang et al. 1996; Scofield et al. 1996).

Corresponding author: M. T. Serra, Centro de Investigaciones Biológicas, Velázquez 144, 28006 Madrid, Spain; Telephone: 34-1-561 18 00; Fax: 34-1-562 75 18; E-mail: cibsy7f@ fresno.csic.es

This article is in the public domain and not copyrightable. It may be freely reprinted with customary crediting of the source. The American Phytopathological Society, 1998.
In Capsicum spp., resistance against tobamoviruses is mediated by an HR with formation of necrotic local lesions (NLLs) at the inoculation sites. This resistance is conferred by four allelic genes at the locus $L\left(L^{1}-L^{4}\right)$ that have increased effectiveness against different tobamoviruses (Boukema 1980, 1982).

Resistance conferred by the $L^{3}$ gene is active against most tobamoviruses except for certain strains of pepper mild mottle virus (PMMoV), such as the Italian strain (PMMoV-I; Wetter et al. 1984). In previous work, we have shown that a functional coat protein $(\mathrm{CP})$ of the S strain of PMMoV (PMMoVS; García-Luque et al. 1993) was required for the elicitation of the $L^{3}$ gene-mediated resistance in $C$. chinense (BerzalHerranz et al. 1995).

Similarly, tobamoviral CPs have been found to be necessary to induce resistance in two other gene-for-gene interactions: the resistance conferred by the $N^{\prime}$ gene in Nicotiana sylvestris (Knorr and Dawson 1988; Saito et al. 1989); and the resistance conferred by the $L^{2}$ gene in $C$. frutescens (de la Cruz et al. 1997). In addition, tobacco mosaic virus (TMV) CP has been also described as the viral factor involved in the elicitation of the HR in Solanum melongena (Dardick and Culver 1997). However, only TMV CP has been identified as the viral elicitor of the $N^{\prime}$ gene-mediated HR (Culver and Dawson 1991; Pfitzner and Pfitzner 1992).

The aim of this work was to establish if the CP of the $\mathrm{S}$ strain of PMMoV is the only viral determinant required to induce the HR in $C$. chinense $\left(L^{3} L^{3}\right)$ and to define it as an elicitor, i.e., as the viral gene product that, on its own, is sufficient to trigger the host resistance response: programmed cell death and activation of defense gene expression (Bent 1996).

With this purpose, the CP of PMMoV-S was expressed in $C$. chinense plants by making use of the potato virus $\mathrm{X}$ (PVX)-based expression system, an unrelated virus (Chapman et al. 1992). In addition to this, the CP of the Italian strain (PMMoV-I) was similarly expressed and used as a control in these experiments.

To create appropriate restriction sites for cloning into the pPC2S vector, the $5^{\prime}$ and $3^{\prime}$ flanking regions of the PMMoV $\mathrm{CP}$ open reading frames (ORFs) were site mutagenized by polymerase chain reaction (PCR). No extra amino acids were present in the CP constructs. The PMMoV-S CP was amplified from the plasmid pSS-2 (spanning from nucleotides 5187 to 6357 of PMMoV-S; Berzal-Herranz et al. 1995). Oligonu- 
cleotide NCPI (5'-CGAATTCCATGGCTTACACAGTT), which contains the ATG CP initiation codon (underlined) within an NcoI restriction site (bold), and the universal M13/pUC sequencing primer 1233 (New England BioLabs, Beverly, MA) were used as $5^{\prime}$ and $3^{\prime}$ mutagenic primers, respectively. The amplified fragment was digested with AflIII, filled in with the Klenow fragment of DNA polymerase, and digested with $\mathrm{NcoI}$. The 593-bp fragment was cloned into the NcoI and EcoRV sites of plasmid pT3T7BM, thus obtaining the intermediate construct pT-CPS. The PMMoV-I CP was mutagenized by PCR, with as template plasmid pI05 (spanning from nucleotides 2100 to 6334 of PMMoV-I; Berzal-Herranz et al. 1995). Oligonucleotides NCPI and ECP2 (5'CGAGATATCTTAATTGCGTTCCATG), containing an EcoRV restriction site (bold), were used as $5^{\prime}$ and $3^{\prime}$ mutagenic primers. The amplified fragment was restricted with $N c o$ I and EcoRV and the 574-bp fragment was inserted into the corresponding sites of plasmid pT3T7BM, thus obtaining construct pT-CPI. To create both pPVX-CPS and pPVX-CPI, the HindIII-blunt-SalI fragments of either plasmid pT-CPS or plasmid pT-CPI were cloned into the unique EcoRV and SalI sites of pPC2S (Fig. 1).

Nicotiana benthamiana Domin plants were inoculated with RNA transcripts generated in vitro from these two constructs and from pPC2S. PVX-CPS and PVX-CPI produced similar symptoms and they accumulated at the same rate as wild-type PVX in these plants (data not shown). Both CPS and CPI proteins were synthesized at high levels in inoculated and upper noninoculated leaves. At 5 days post inoculation (d.p.i.), systemically infected leaves were used to inoculate $C$. frutescens $\left(L^{2} L^{2}\right)$ and $C$. chinense $\left(L^{3} L^{3)}\right.$ plants. The concentration of the expressed CPs in plants used as source of inoculum was determined by double antibody sandwich enzyme-linked immuno-

\begin{tabular}{|c|c|c|c|}
\hline \multirow[b]{2}{*}{$\mathrm{PVX2C2S}$} & & \multicolumn{2}{|c|}{$\begin{array}{c}\text { Symptoms on } \\
\text { Capsicum }\end{array}$} \\
\hline & Eco RV Sal I & $L^{2} L^{2}$ & $L^{3} L^{3}$ \\
\hline $166 \mathrm{~K}$ & $25 \mathrm{~K}$ & $\mathbf{s}$ & $\mathbf{S}$ \\
\hline
\end{tabular}

\section{PVX-CPS}

\begin{tabular}{c|c|c|c|c|}
\hline $166 \mathrm{~K}$ & $25 \mathrm{~K}$ & $\mathrm{BK}$ & $\mathrm{CPS}$ & $\mathrm{CP}$ \\
\hline $12 \mathrm{~K}$ &
\end{tabular}

$\mathbf{S}$

NLL

\section{PVX-CPI}

\begin{tabular}{ll|l|l|l|l|}
\hline $166 \mathrm{~K}$ & $25 \mathrm{~K}$ & $\mathrm{BK}$ & $\mathrm{CPI}$. & $\mathrm{CP}$ \\
\hline $12 \mathrm{~K}$ & &
\end{tabular}

$\mathbf{S}$

Fig. 1. Pathogenicity of the chimeric constructs of potato virus $X$ (PVX) and pepper mild mottle virus (PMMoV) coat proteins (CPs). Representation of the hybrid viral genomes used in this study on left. Representation of the PVX genome organization at top. Dotted boxes correspond to PMMoV-S and PMMoV-I CP genes. On the right, the symptomatology observed on Capsicum frutescens $\left(L^{2} L^{2}\right)$ and $C$. chinense $\left(L^{3} L^{3}\right)$ plants inoculated with the hybrid viruses shown on the left. NLL, necrotic local lesions; S, systemic infection. sorbent assay (DAS-ELISA) and Western blot (immunoblot) analysis as described in Berzal-Herranz et al. (1995), with specific antibodies against PVX (Boehringer, Barcelona, Spain) and PMMoV (Alonso et al. 1989) CPs (data not shown).

In $C$. frutescens, PMMoV-S is able to spread systemically. In this host, no visible symptoms were observed in the inoculated leaves of plants infected with either the PVX or PVXCPS chimeric virus. At 10 d.p.i., all inoculated plants developed systemic symptoms of mosaic (Fig. 1; data not shown). PVX and PMMoV-S CPs were detected by Western blot analysis in both the inoculated and upper noninoculated leaves of these plants at 7 and 15 d.p.i. The accumulation of both viruses was similar (Fig. 2A). Additionally, the presence of PMMoV-S CP-related sequences in these leaves was also detected by a reverse transcription (RT)-PCR assay on total leaf RNA extracts with a pair of primers, CP1 and CP2, as described in Tenllado et al. (1994). A cDNA fragment of $395 \mathrm{bp}$ was amplified from both inoculated and systemically infected leaves of PVX-CPS-infected plants (Fig. 2B).

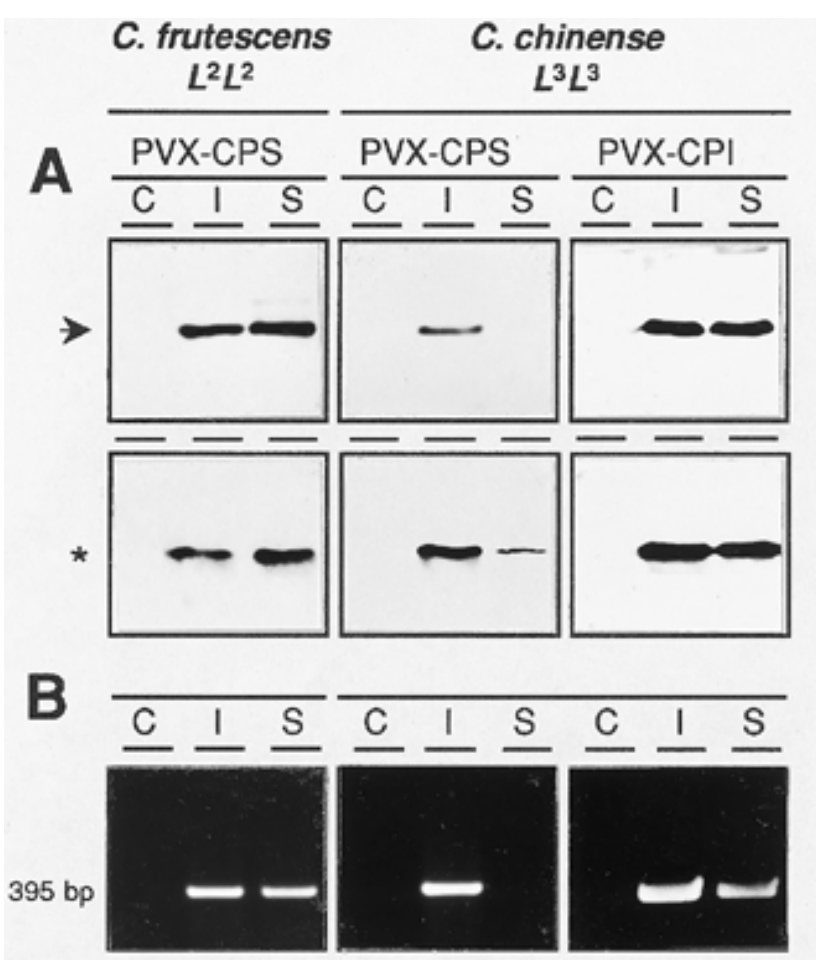

Fig. 2. Detection of viral coat proteins (CPs) in Capsicum frutescens plants inoculated with potato virus X (PVX)-CPS hybrid virus and in $C$. chinense plants inoculated with PVX-CPS and PVX-CPI hybrid viruses. A, Western blot (immunoblot) analysis of pepper mild mottle virus (PMMoV)-S, PMMoV-I, and PVX CPs. Plant protein extracts were prepared at 5 days post inoculation (d.p.i.) from the inoculated leaves and at 15 d.p.i. from the upper noninoculated leaves. Proteins were separated on a $17 \%$ sodium dodecyl sulfate-polyacrylamide gel electrophoresis (SDS-PAGE) system (Laemmli 1970) and electrotransferred to nitrocellulose. PMMoV-S and PMMoV-I CPs were detected with PMMoVspecific antiserum (Alonso et al. 1989), and PVX CP by a commercial antiserum (Boehringer, Barcelona, Spain). CP bands were visualized with the Enhanced Chemiluminiscence System (ECL Amersham, Amersham Place, U.K.): (arrow) PMMoV CPs; (asterisk) PVX CP; C, control, mock inoculated; I, inoculated leaves; S, upper noninoculated leaves. B, Reverse transcription-polymerase chain reaction (RT-PCR) analysis of PMMoV$\mathrm{S}$ or PMMoV-I CPs. RT-PCR amplification performed as described in Tenllado et al. (1994) on total leaf RNA extracted at times stated. Amplified fragments were electrophoresed on an $0.8 \%$ agarose gel. 
These data revealed that in Capsicum spp. $L^{2}$ plants the pathogenic behavior of both PVX and PVX-CPS is identical with respect to symptom expression, viral spread, and accumulation level in both inoculated and upper noninoculated leaves.

In contrast to this, inoculation of PVX-CPS onto $C$. chinense leaves developed NLLs at 5 d.p.i. similar to those induced by PMMoV-S, whereas inoculation with PVX did not result in the development of any visible symptoms in this time period (Fig. 1).

As described above, the presence of viral CPs and PMMoV-S CP-related nucleotide sequences was examined at 5 and 15 d.p.i. in the inoculated and the upper noninoculated leaves of $C$. chinense plants. In PVX-infected plants, the PVX CP was detected in both types of leaves. In PVX-CPS-inoculated plants, PVX CP was detected in the inoculated leaves as well as in the upper noninoculated leaves of some (approximately 20\%) of the inoculated plants. In contrast, the PMMoV-S CP and PMMoV-S $\mathrm{CP}$-related sequences could only be detected in the inoculated leaves, but not in the upper noninoculated leaves (Fig. 2A and $B)$. The presence in the upper noninoculated leaves of the PVX CP but not the PMMoV-S CP could be produced by the formation of PVX vector derivatives that have lost the inserted foreign sequence, a phenomenon previously observed when this vector was used (Chapman et al. 1992).

These data show that the presence of the CP gene of the viral strain that induces the HR is sufficient to localize the chimeric virus PVX-CPS to the inoculated leaves of $C$. chinense $\left(L^{3} L^{3}\right)$ plants, thus mimicking the behavior of the avirulent virus PMMoV-S in this host. In addition, these results show the specificity of the host reaction, so that PVX molecules without PMMoV-S CP sequence can escape the $L^{3}$ gene response.

To further analyze the specificity of the host response, $C$. chinense plants were also inoculated with a PVX derivative containing the PMMoV-I CP gene (PVX-CPI). These plants did not develope any visible symptoms at 5 d.p.i. in the inoculated leaves (Fig. 1). The CPs of both PVX and PMMoV-I were detected by Western blot analysis in both the inoculated and upper noninoculated leaves (Fig. 2A), and the PMMoV-I $\mathrm{CP}$ gene was also detected in both types of leaves (Fig. 2B). The data conclusively show that, in the absence of the $L^{3} A v r$ gene, the chimeric virus is able to spread through the plant.

To further investigate the molecular mechanisms underlying the recognition events that trigger $C$. chinense $L^{3}$ genemediated plant defense reaction against the tobamoviruses, we examined whether the PMMoV-S CP itself is sufficient to trigger the HR in this host.

To establish if the PMMoV CP is able to induce the cell death associated with the HR, we have employed a transient expression method similar to that reported by Mindrinos et al. (1994) and Gopalan et al. (1996) to express either PMMoV-S or PMMoV-I CPs in C. chinense leaves. The biolistic transient expression system utilized is based on the prediction that the induction of a hypersensitive cell death by the expression of a protein elicitor will reduce the accumulation of a $\beta$ glucuronidase (GUS) reporter gene cointroduced simultaneously in the same plant cell, when this gene is expressed under the control of the constitutive $35 \mathrm{~S}$ promoter. Thus, the plasmids pMJD82(CPS) and pMJD82(CPI) were constructed by cloning the $\mathrm{CP}$ gene of both the $\mathrm{S}$ and I strains of PMMoV in the plant expression vector, pMJD82. In addition to this, the GUS reporter gene was cloned in the same vector, creating the
pMJD82(GUS) construct. Expression of the inserted sequences in the pMJD82 vector is controlled by the enhanced cauliflower mosaic virus 35S promoter (Dowson Day et al. 1994).

To create both pMJD82(CPS) and pMJD82(CPI), the NcoI-

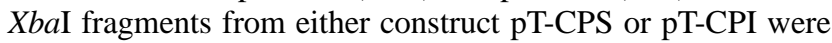
inserted into the corresponding sites of plasmid pMJD82.

Five-week-old $C$. chinense leaves, from plants grown in vitro, were co-bombarded with pMJD82 plus pMJD82(GUS) as a control, or with either pMJD82(CPS) plus pMJD82(GUS) or pMJD82(CPI) plus pMJD82(GUS).

The transient expression assays were performed on the biolistic PSD-1000/He system of Bio-Rad (Hercules, CA) and $1,100 \mathrm{lb} / \mathrm{in}^{2}$ rupture disks. The $1-\mu \mathrm{m}$ gold particles were prepared according to Klein et al. (1988). Five micrograms of plasmids pMJD82, pMJD82-CPS, and CP-I and $2.5 \mu \mathrm{g}$ of plasmids pMJD82(GUS) and pDE1001gn1/GUS were used. After each bombardment, $C$. chinense leaves were maintained in petri dishes on water-soaked filter paper. The histochemical analysis of GUS activity was performed as in Jefferson et al. (1987).

At 3 to 5 days post bombardment, NLLs appeared (Fig. 3B) in leaves inoculated with the plasmid pMJD82(CPS) containing the $\mathrm{CP}$ of the avirulent strain, but not in those leaves in which either the GUS gene or the $\mathrm{CP}$ from the compatible strain were delivered (Fig. 3A and C). In these experiments, delivery of gold particles is not evenly distributed over the entire leaf surface, as can be inferred by the size and distribution of the blue spots detected in the GUS assay (Fig. 3). Therefore, and as a result of the expression of the CP from the avirulent strain, the death of a cluster of neighboring cells that were inoculated by the gold particles could lead to the formation of necrotic lesions. However, the possibility remains open that necrotic lesions might arise by the transmission of signals originating in the transfected cell that activates programmed cell death in the surrounding cells (Bent 1996; Dangl et al. 1996; Greenberg 1997).

Histochemical assay for GUS activity was carried out at several time intervals after bombardment. Blue spots were visible after $8 \mathrm{~h}$ post bombardment (h.p.b.) in all cases, although the number of spots in leaves inoculated with pMJD82 plus pMJD82(CPS) (Fig. 3E) was lower than those observed in leaves inoculated with either pMJD82(GUS) or pMJD82(GUS) plus pMJD82(CPI) (Fig. 3D and F). At all times analyzed, blue spots of increased intensity were detected for these two later inocula (Fig. 3D, G, J and F, I, L). By contrast, no blue spots could be viewed after 24 h.p.b. in leaves inoculated with construct pMJD82(GUS) plus pMJD82(CPS) (Fig. 3K), indicating that GUS accumulation was reduced in these leaves. These data show that PMMoV-S CP itself is able to trigger the programmed cell death associated with the HR.

Reduction of GUS activity cannot be ascribed to posttranscriptional modifications of its mRNA, since GUS activity was readily detectable when the gene was expressed from a different promoter (see below). Decreased GUS activity might reflect a reduction in the level of the transcription directed by the constitutive $35 \mathrm{~S}$ promoter in those cells undergoing programmed cell death.

Finally, to assess if the HR induced by the PMMoV-S CP is also associated with the induction of defense gene expression, we performed a similar co-bombardment experiment with a reporter GUS gene expressed under the control of the $\beta-1-3$ glucanase promoter from the gnl gene of $N$. plumbaginifolia. 

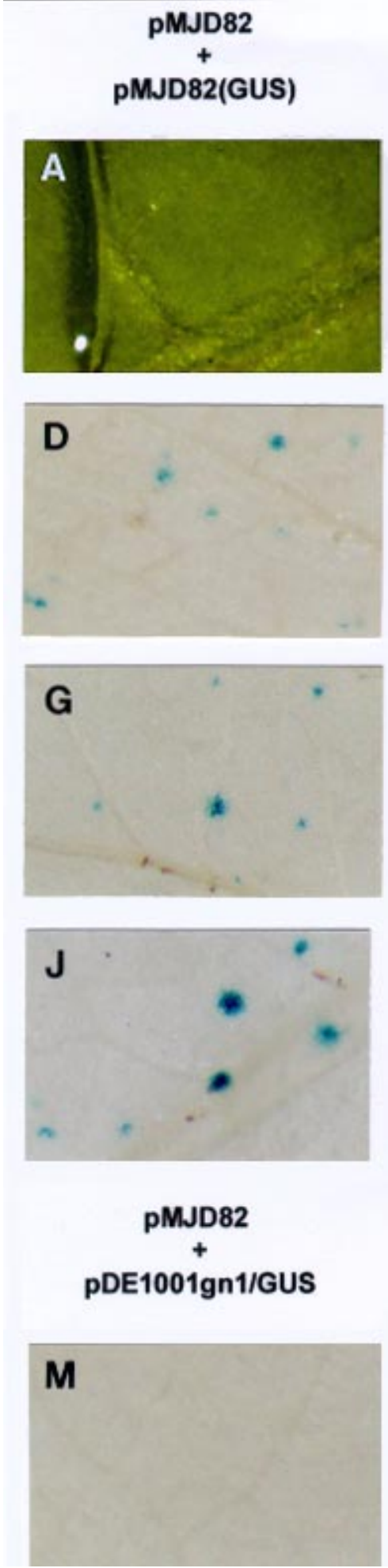
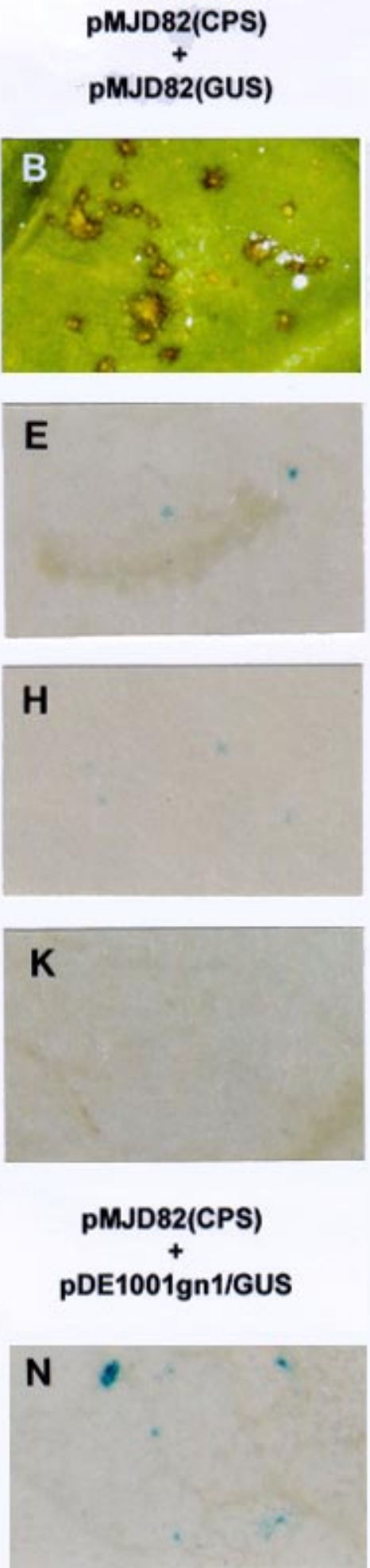

PMJD82(CPI)

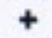

pMJD82(GUS)
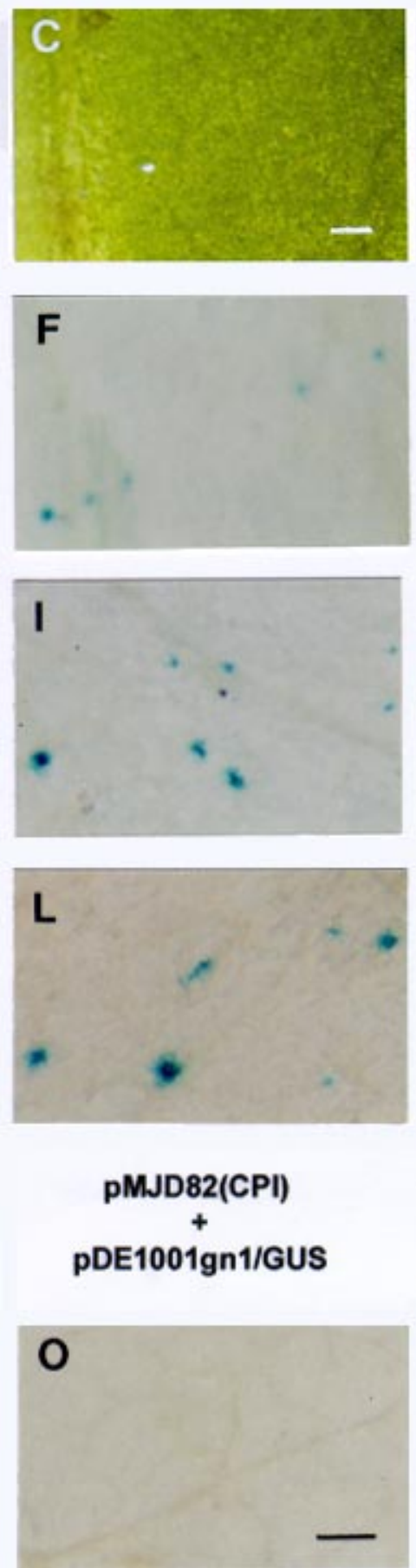

Fig. 3. Transient expression of pepper mild mottle virus (PMMoV)-S and PMMoV-I coat proteins (CPs) in Capsicum chinense leaves. A-C, Symptoms induced at 4 days post bombardment by the transient expression of PMMoV-S (B) and PMMoV-I (C) CPs in C. chinense leaves. A, Control plant. D-L, Effect of transient expression of PMMoV-S $(\mathbf{E}, \mathbf{H}, \mathbf{K})$ and PMMoV-I (F, I, L) CPs upon $\beta$-glucuronidase (GUS) activity, expressed from a constitutive promoter, in $C$. chinense leaves. D, G, and J, Control plants. GUS assay performed at 8 (D-F), 16 (G-I), and 24 (J-L) h post bombardment (h.p.b.). Leaves were co-bombarded with plasmids pMJD82 (control vector) plus pMJD82(GUS) (control plants) (A, D, G, and J), pMJD82(CPS) plus pMJD82(GUS) (B, E, H and K), and pMJD82(CPI) plus pMJD82(GUS) (C, F, I, and L). M-O, Effect of transient expression of PMMoV-S (N) and PMMoV-I (O) CPs on GUS activity, when directed by a hypersenstive response (HR)-inducible promoter, in C. chinense leaves. M, Control plants. Leaves were co-bombarded with plasmids pMJD82 (control vector) plus pDE1001gn1/GUS (M), pMJD82(CPS) plus pDE1001gn1/GUS (N), and pMJD82(CPI) plus pDE1001gn1/GUS (O). GUS activity was determined at 24 h.p.b. Bars $=250 \mu \mathrm{m}$. 
The expression directed by the gnl promoter was found to be strongly induced in N. tabacum transgenic plants, during the HR elicited by Pseudomonas syringae pv. syringae (Castresana et al. 1990). Histochemical analysis of GUS activity revealed the presence of blue spots in leaves 24 h.p.b. with constructs gn1/GUS and pMJD82(CPS) (Fig. 3N), but not when either the gn1/GUS chimeric gene alone or in combination with pMJD82(CPI) was delivered onto the plants (Fig. 3M and $\mathrm{O}$ ). These results show that the transient expression of only the PMMoV-S CP in C. chinense leaves is able to activate the expression of nonspecific plant defense gene, another hallmark of the HR induction.

From our data we conclude that the PMMoV-S CP is a strainspecific elicitor triggering an HR in Capsicum spp. harboring the complementary $L^{3}$ resistance gene against tobamoviruses. As for the TMV CP and PVX CP, which are the elicitors of the resistance conferred by the $N^{\prime}$ gene in $N$. sylvestris (Culver and Dawson 1991) and the $R x 1$ gene in potato (Bendahmane et al. 1995), respectively, the PMMoV-S CP is another viral CP that acts as an elicitor in a gene-for-gene resistance system.

\section{ACKNOWLEDGMENTS}

We thank D. C. Baulcombe (Sainsbury Laboratory, Norwich, UK) for the kind gift of plasmid pPC2S; C. Castresana (CNB, CSIC, Madrid) for providing plasmid pDE1001 gnl/GUS and for helpful discussion; M. J. Dowson Day (University of Sussex, Brighton, UK) for the gift of plasmid pMJD82; G. Vancaneyt and J. J. Sánchez-Serrano (CNB, CSIC, Madrid) for their help with the bombardment experiments; and M. Fontela and V. Muñoz for photographic work. The work was supported by grants from the CICYT (AGF95-0696) and from the CAM (07B/0034/1997). P. G. is the recipient of a CAM predoctoral fellowship.

\section{LITERATURE CITED}

Alonso, E., García-Luque, I., Avila-Rincón, M. J., Wicke, B., Serra, M. T., and Díaz-Ruíz, J. R. 1989. A tobamovirus causing heavy losses in protected pepper crops in Spain. J. Phytopathol. 125:67-76.

Bendahmane, A., Köhm, B. A., Dedi, C., and Baulcombe, C. 1995. The coat protein of potato virus $\mathrm{X}$ is a strain-specific elicitor of $\mathrm{Rx} 1$ mediated virus resistance in potato. Plant J. 8:933-941.

Bent, A. F. 1996. Plant disease resistance genes: Function meets structure. Plant Cell 8:1757-1771.

Berzal-Herranz, A., De la Cruz, A., Tenllado, F., Díaz-Ruíz, J. R., López L., Sanz, A. I., Vaquero, C., Serra, M. T., and García-Luque, I. 1995. The Capsicum $\mathrm{L}^{3}$ gene-mediated resistance against the tobamoviruses is elicited by the coat protein. Virology 209:498-505.

Bol, J. F., Linthorst, H. J., and Cornelissen, B. J. C. 1990. Plant pathogenesis-related proteins induced by virus infection. Annu. Rev. Phytopathol. 28:113-138.

Boukema, I. W. 1980. Allelism of genes controlling resistance to TMV in Capsicum L. Euphytica 29:433-439.

Boukema, I. W. 1982. Resistance to TMV in Capsicum chacoense Hunz. is governed by an allele of the L-locus. Capsicum Newsl. 3:47-48.

Castresana, C., de Carvalho, F., Gheysen, G., Habets, M., Inzé, D., and Van Montagu, M. 1990. Tissue-specific and pathogen-induced regulation of a Nicotiana plumbaginifolia $\beta$-1,3-glucanase gene. Plant Cell 2:1131-1143.

Chapman, S., Kavanagh, T., and Baulcombe, D. C. 1992. Potato virus X as a vector for gene expression in plants. Plant J. 2:549-557.

Culver, J. N., and Dawson, W. O. 1991. Tobacco mosaic virus elicitor coat protein genes produce a hypersensitive phenotype in transgenic Nicotiana sylvestris plants. Mol. Plant-Microbe Interact. 4:458-463.

Dangl, J. L., Dietrich, R. A., and Richberg, M. H. 1996. Death don't have no mercy: Cell death programs in plant-microbe interactions. Plant Cell 8:1793-1807.

Dardick, C. D., and Culver, J. N. 1997. Tobamovirus coat proteins: Elicitors of the hypersensitive response in Solanum melongena (eggplant). Mol. Plant-Microbe Interact. 10:776-778. de la Cruz, A., López, L., Tenllado, F., Díaz-Ruíz, J. R., Sanz, A. I., Vaquero, C., Serra, M. T., and García-Luque, I. 1997. The coat protein is required for the elicitation of the Capsicum $\mathrm{L}^{2}$ gene-mediated resistance against the tobamoviruses. Mol. Plant-Microbe Interact. 10:107-113.

Dowson Day, M. J., Ashurst, J. L., and Dixon, R. A. 1994. Plant expression cassettes for enhanced translational efficiency. Plant Mol. Biol. Rep. 12:347-357.

Flor, H. H. 1971. Current status of the gene-for-gene concept. Annu. Rev. Phytopathol. 9: 275-296.

Gabriel, D. W., and Rolfe, B. G. 1990. Working models of specific recognition in plant-microbe interactions. Annu. Rev. Phytopathol. 28: 365-391.

García-Luque, I., Ferrero, M. L., Rodríguez, J. M., Alonso, E., de la Cruz, A., Sanz, A. I., Vaquero, C., Serra, M. T., and Díaz-Ruíz, J. R. 1993. The nucleotide sequence of the coat protein genes and $3^{\prime}$ noncoding regions of two resistance-breaking tobamoviruses in pepper shows that they are different viruses. Arch. Virol. 131:75-88.

Goodman, R. N., and Novacky, A. J. 1994. The Hypersensitive Reaction in Plants to Pathogens. A Resistance Phenomenon. American Phytopathological Society, St. Paul, MN.

Gopalan, S., Bauer, D. W., Alfano, J. R., Loniello, A. O., He, S. Y., and Collmer, A. 1996. Expression of the Pseudomonas syringae avirulence protein AvrB in plant cells alleviates its dependence on the hypersensitive response and pathogenicity (Hrp) secretion system in eliciting genotype-specific hypersensitive cell death. Plant Cell 8: 1095-1105.

Greenberg, J. T. 1997. Programmed cell death in plant pathogen interactions. Annu. Rev. Plant Physiol. Plant Mol. Biol. 48:525-545.

Jefferson, R. A., Kavanagh, T. A., and Bevan, M. W. 1987. GUS fusions: $\beta$-Glucuronidase as a sensitive and versatile gene fusion marker in higher plants. EMBO J. 6:3901-3907.

Keen, N. T. 1990. Gene-for-gene complementarity in plant-pathogen interactions. Annu. Rev. Genet. 24:447-463.

Klein, T. M., Gradziel, T., Fromm, M. E., and Sanford, J. C. 1988. Factors influencing gene delivery into Zea mays cells by high-velocity microprojectiles. Bio/Technology. 6:559-563.

Klement, Z. 1982. Hypersensitivity. Pages 149-177 in: Phytopathogenic Prokaryotes. M. S. Mount and G. H. Lacy, eds. Academic Press, New York.

Knorr, D. A., and Dawson, W. O. 1988. A point mutation in the tobacco mosaic virus capsid protein gene induces hypersensitivity in Nicotiana sylvestris. Proc. Natl. Acad. Sci. USA 85:170-174.

Laemmli, U.K. 1970. Cleavage of structural proteins during the assembly of the head of bacteriophage T4. Nature 227:680-685.

Mindrinos, M., Katagiri, F., Yu, G. L., and Ausubel, F. M. 1994. The A. thaliana disease resistance gene RPS2 encodes a protein containing a nucleotide-binding site and leucine-rich repeats. Cell 78:1089-1099.

Pfitzner, U. M., and Pfitzner, A. J. P. 1992. Expression of a viral avirulence gene in transgenic plants is sufficient to induce the hypersensitive reaction. Mol. Plant-Microbe Interact. 5:318-321.

Saito, T., Yamanaka, K., Watanabe, Y., Takamatsu, N., Mashi, T., and Okada, Y. 1989. Mutational analysis of the coat protein gene of tobacco mosaic virus in relation to hypersensitive response in tobacco plants with the $\mathrm{N}^{\prime}$ gene. Virology 173:11-20.

Scofield, S. R., Tobias, C. M., Rathjen, J. P., Chang, J. H., Lavelle, D. T., Michelmore, R. W., and Staskawicz B. J. 1996. Molecular basis of gene-for-gene specificity in bacterial speck disease of tomato. Science 274:2063-2065.

Staskawicz, B. J., Ausubel, F. M., Baker, B. J., Ellis, J. G., and Jones, J. D. 1995. Molecular genetics of plant disease resistance. Science 268: 661-667.

Stinzi, A., Heitz, T., Prasad, V., Wiedemann-Merdinoglu, S., Kauffmann, S., Geoffroy, P., Legrand, M., and Fritig, B. 1993. Plant 'pathogenesis-related' proteins and their role in defense against pathogens. Biochimie 75:687-706.

Tang, X. Y., Frederick, R. D., Zhou, J. M., Halterman, D. A., Jia, Y. L., and Martin, G. B. 1996. Initiation of plant disease resistance by physical interaction of AvrPto and Pto kinase. Science 274:2060-2063.

Tenllado, F., García-Luque, I., Serra, M. T., and Díaz-Ruíz, J. R. 1994. Rapid detection and differentiation of tobamoviruses infecting Lresistant genotypes of pepper by RT-PCR and restriction analysis. J. Virol. Methods 47:165-174.

Wetter, C., Conti, M., Altschuh, D., Tabillion, R., and van Regenmortel, M. H. V. 1984. Pepper mild mottle virus, a tobamovirus infecting pepper cultivars in Sicily. Phytopathology 74:405-410. 